\title{
0 trabalho do assistente social no Programa Bolsa Família: desafios ao Código de Ética profissional
}

\section{The social worker's work in the Family Allowance Program: challenges to the professional code of ethics}

\author{
Bruna Carnelossi \\ Doutoranda pelo Programa de Estudos Pós-Graduados em Serviço Social da PUC-SP/São Paulo, Brasil. \\ bru-carnelossi@uol.com.br
}

\begin{abstract}
Resumo: O artigo analisa o trabalho do assistente social na execução do Programa Bolsa Família (PBF) no âmbito da política de assistência social. Apreende os desafios na efetivação dos valores e princípios do Código de Ética do Serviço Social perante as atribuições exigidas na execução das políticas sociais contemporâneas. A partir de uma pesquisa bibliográfica e documental, observa um campo de tensão entre os valores intrínsecos ao formato condicionado e focalizado do PBF, o Código de Ética profissional e a política de assistência social.
\end{abstract}

Palavras-chave: Serviço Social. Trabalho. Código de Ética. Políticas sociais. Bolsa Família. Assistência social.

\begin{abstract}
In this article it is analyzed the social worker's work while running the Family Allowance Program (Programa Bolsa Família - PBF) within the Social Service policy, focusing the ethical dimension of the professional practice. It involves the discussion of the challenges to actualize the values and principles of the Social Work code of ethics before the assignments required for the execution of current social policies. From a bibliography and data research it is observed a tension field among the intrinsic values of PBF conditioned and focused format, the professional code of ethics and the Social Service policy.
\end{abstract}

Keywords: Social Work. Work. Code of ethics. Social policies. Family Allowance Program. Social Service.

\section{Introdução}

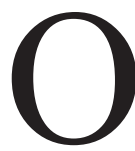

presente artigo analisa o trabalho do assistente social na execução do Programa Bolsa Família (PBF) no âmbito da política de assistência social. O foco da análise prioriza a dimensão ética implícita no fazer 
técnico-operativo envolvido nas intervenções profissionais de assistentes sociais executores das políticas sociais contemporâneas, com destaque para o PBF. Nesse sentido, busca apreender os desafios na efetivação dos valores e princípios do Código de Ética do Serviço Social, que devem ser observados e respeitados por assistentes sociais e instituições empregadoras perante as demandas e atribuições exigidas na execução das políticas e programas sociais de formato focalizado e condicionado.

Discorrer sobre os desafios para a consolidação dos princípios do Código de Ética do Serviço Social no âmbito da intervenção profissional na execução do PBF na esfera da política de assistência social implica reconhecer que a inserção e atribuições do assistente social nesse sentido não se processam isoladas e desconectadas das transformações conceituais e operacionais que afetam as políticas sociais contemporâneas, cujo direcionamento atual é orientado por intervenções minimalistas, focalizadas e de ativação dos mais pobres através de condicionalidades. Para tanto, pretende-se efetuar uma breve caracterização das políticas sociais contemporâneas regidas pela lógica do workfare.

Neste estudo privilegia-se a variável ética presente na execução das políticas sociais contemporâneas, caracterizadas pelo modelo que impõe atividades de retribuição dos benefícios recebidos do Estado por parte dos beneficiários e também exige do trabalhador, executor desse tipo de programa, o desenvolvimento da ação designada em documentos oficiais como "trabalho social com famílias", com destaque para as famílias que descumprem as condicionalidades. Observa-se que a convivência entre os valores intrínsecos à execução das políticas sociais contemporâneas e os princípios do Código de Ética do Serviço Social nem sempre é harmônica e, portanto, impõe desafios ao assistente social trabalhador das diversas políticas sociais, com destaque neste artigo para a política de assistência social.

\section{Distintivos das políticas sociais contemporâneas versus política de assistência social}

A reconfiguração das políticas sociais na contemporaneidade ataca os princípios universais das políticas sociais tradicionais (guiadas pela lógica do 
Welfare State), passando a selecionar grupos e segmentos em função de características e/ou méritos, em detrimento da universalização dos direitos sociais. Segundo Sposati (2011, p. 108), "este é o momento da conversação das políticas sociais de direitos em políticas de combate à pobreza que se voltam para a redução da miséria sem alcance dos direitos sociais".

Essa nova geração das políticas sociais é regida pelo ideário de um modelo de políticas sociais denominado Workfare State, em contraponto às políticas sociais de cunho universal e incondicional. O termo workfare - junção das palavras inglesas work (trabalho) + welfare (bem-estar) - foi criado nos Estados Unidos em 1960 para designar o bem-estar em troca ou à custa de trabalho. Para Peck (2003), o "método" e a "filosofia" intrínsecos à ideia do Workfare State se caracterizam pela materialidade de políticas sociais ativadoras do mérito competitivo e excludente (em contraposição ao direito universal), concebidas para incutir nos seus destinatários o hábito do trabalho assalariado, da busca resignada por empregos, além da submissão à disciplina dos rotineiros treinamentos profissionais exigidos por um mercado de trabalho inconstante. Essa regulação contemporânea das políticas sociais é partidária de uma "racionalidade de retribuição expressa na obrigatoriedade de participação dos cidadãos em medidas de ativação voltadas ao mercado de trabalho" (Moser, 2011, p. 3), ou em medidas que condicionam benefícios sociais a determinados comportamentos dos beneficiários.

O rebatimento desse modelo de política social no campo do Estado é definido por Jessop (apud Pereira, 2014, p. 20) quando afirma: "Está havendo uma contínua e crescente passagem de um tipo capitalista de Estado (social de direito), para outro tipo capitalista de Estado (neoliberal/meritocrático/laborista), ou do que vem sendo identificado como transição do Welfare State, de estilo keynesiano/ fordista, para o Workfare State, de estilo schumpeteriano/pós-fordista".

Em suma, as características das políticas sociais contemporâneas designadas pela lógica do Workfare State se concentram em três aspectos:

1) Obrigatoriedade de participação dos cidadãos em medidas de ativação voltadas para o mercado de trabalho.

2) Condicionamento dos benefícios sociais a determinados comportamentos do beneficiário, como os do PBF, que exigem contrapartidas geralmente nas áreas da educação e saúde para o recebimento do benefício. 
3) A focalização na pobreza e na extrema pobreza, definidas em geral por restritivas per capitas.

Ao abordar a política social sob as perspectivas do direito e do mérito, Pereira (2014, p. 20) afirma que na mudança de estado de tipo welfare para workfare impera uma ortodoxia moralista que nega aos trabalhadores a devida proteção social pública ao instituir uma ética de proteção pautada na autorresponsabilização dos indivíduos, esvaziando o Estado de seu papel. Nessa ambiência, segundo a autora: "Construíram-se ortodoxias baseadas na velha doutrina do darwinismo social, concebida no século 20, segundo a qual os pobres devem autossatisfazer as suas necessidades; ou, então, pagarem pelos auxílios públicos, recebidos, o que é incompatível com a concepção incondicional e anticontratual de direito social".

Cabe aqui pontuar, diante a dimensão temporal da contemporaneidade das políticas sociais, que a tendência focalizada e condicionada, embora destoante das políticas que as antecederam, de cunho universalista, encontram sua gênese na história em 1834, na Inglaterra, quando se institui as workhouses (casas de trabalho), em detrimento dos benefícios incondicionais. Segundo Vanderborght e Van Parijs (2006, p. 38) foi nesses espaços - workhouses - que se restabeleceram as ações estigmatizadoras da indigência e punitivas para quem não se adequasse ao trabalho.

Tendo por pressuposto que a presença de valores é inegável nas ações da vida social (Barroco, 2012), também a transição do Welfare State para o Workfare State repercute no campo dos valores e princípios intrínsecos à concepção, gestão e execução das políticas sociais e, consequentemente, presentes no cotidiano do trabalho do assistente social atuante na política de assistência social, em especial no caso da execução do PBF. Entretanto, esse formato contemporâneo das políticas sociais, delineado por uma ortodoxia moralista, se confronta com os valores e os princípios historicamente construídos no processo de consolidação do Serviço Social, comprometidos com a construção de uma nova "sociabilidade".

1. A nova sociabilidade, segundo a publicação do CFESS (2009) designada por Parâmetros para atuação de assistentes sociais na política de assistência social, está fundamentada nas seguintes lutas: no 


\subsection{Especificidades da política de assistência social}

A proposta deste artigo não analisa o $\mathrm{PBF}$ desconectado de seu lócus de execução; os serviços socioassistenciais, especialmente o Centro de Referência de Assistência Social (Cras) e o Proteção e Atendimento Integral à Família (Paif).

Referenciar a assistência social enquanto política pública constitucionalmente reconhecida pelo Estado brasileiro ${ }^{2}$ implica reconhecer sua expansão por todo o território nacional, principalmente a partir da década de 1990 e nas primeiras do terceiro milênio, período em que se institui através de diversos marcos regulatórios. ${ }^{3}$

Segundo Lavinas (2012), a instituição da política pública de assistência social expressa no Brasil o avanço da expansão e o reconhecimento dos direitos sociais, visto que seus princípios universais representam a ampliação da proteção social e da cidadania para todos, independentemente do vínculo empregatício/contributivo.

Entretanto, essa trajetória recente de instituição e consolidação acontece concomitante à ampliação de programas sociais no âmbito do Poder Executivo, cujos princípios e valores intrínsecos são contrastantes e antagônicos à política de assistência social fundada no patamar de política pública.

Nesse cenário, a trajetória de implantação e defesa da assistência social se confronta com os princípios das políticas sociais contemporâneas, condicionadas

reconhecimento da liberdade, autonomia, emancipação e plena expansão dos indivíduos sociais; na defesa intransigente dos direitos humanos e na recusa do arbitrio e do autoritarismo; na ampliação e consolidação da cidadania. Com vistas à garantia dos direitos das classes trabalhadoras; na defesa da radicalização da democracia, enquanto socialização da participação política e da riqueza socialmente produzida; no posicionamento em favor da equidade e justiça social, que asseguram a universalidade de acesso aos bens e serviços, bem como sua gestão democrática; e no empenho pela eliminação de todas as formas de preconceito (CFESS, 2009, p.14; grifos nossos).

2. A Constituição Federal brasileira de 1988, em seu artigo 194, dispõe: "A Seguridade Social compreende um conjunto integrado de ações de iniciativa dos Poderes Públicos e da sociedade, destinadas a assegurar os direitos relativos à saúde, à previdência e à Assistência Social” (Brasil, 1988, p. 117).

3. Foi regulamentada pela Lei n. 8.742/1993 — Lei Orgânica de Assistência Social (Loas), pela Política Nacional de Assistência Social, pela Norma Operacional Básica, pelo Sistema Único de Assistência Social (Suas) etc. 
e focalizadas nos mais pobres, portanto, contrárias ao princípio fundante da assistência social no marco da seguridade social.

A distinção da natureza dos princípios da política de assistência social e das políticas sociais contemporâneas é importante quando buscamos analisar a dimensão ética e político-ideológica do agir profissional no trato com os beneficiários do PBF, em contraponto com os valores e princípios do Código de Ética, pois a atuação exigida ao profissional na execução do PBF é divergente dos princípios da política de assistência social e transgressora dos valores do Código de Ética dos assistentes sociais, como demonstraremos a seguir. Portanto, registra-se um confronto de princípios que coloca de um lado a política de assistência social (influenciada pela lógica universal e incondicional) e o Código de Ética do Serviço Social, e de outro lado a lógica dos atuais programas de transferência de renda focalizados e condicionados, como é o caso do PBF.

Destaca-se a importância de ponderar sobre esse campo de tensão, pois, do contrário, corre-se o risco de se associar diretamente assistência social à lógica de acumulação capitalista intrínseca às políticas sociais contemporâneas, pressuposto esse incorporado por parte da categoria profissional, "que rejeita reconhecer a política de assistência social como campo do exercício profissional digno" (Sposati, 2013, p. 662).

Embora uma parte da categoria profissional do Serviço Social não legitime a política de assistência social, historicamente essa categoria profissional se posiciona em sua defesa - guiada pela compreensão universal de direitos - e reconhece o importante papel do trabalho de assistentes sociais na consolidação da assistência social como direito de cidadania. Para o Conselho Federal de Serviço Social, no documento intitulado Parâmetros para atuação de assistentes sociais na politica de assistência social (CFESS, 2009), o processo de instituição da assistência social como direito social e política de seguridade social a transportou, da concepção de favor, da pulverização e dispersão, ao estatuto de política pública e da ação focal e pontual à dimensão da universalização. Portanto, o posicionamento da categoria profissional em defesa da assistência social enquanto política de direito social revela que os valores e princípios da assistência social não são díspares dos valores firmados pelo Código de Ética do Serviço Social, que articulam "direitos amplos, universais e equânimes, orientados pela perspectiva de superação das desigualdades sociais 
e pela igualdade de condições, e não apenas pela instituição parca, insuficiente e abstrata igualdade de oportunidades, que constitui a fonte do pensamento liberal" (Ibidem, p. 11).

\subsection{Bolsa Família e controle dos mais pobres}

A institucionalização e a operacionalização das políticas sociais contemporâneas têm impactado na materialidade dos serviços e benefícios sociais, de modo a delimitá-los e restringi-los em consonância com a tendência mundial da lógica de acumulação de capital.

No Brasil, o $\mathrm{PBF}^{4}$ é o exemplo mais contundente desse modelo de política social, cuja gestão e execução envolve diretamente o exercício profissional dos assistentes sociais no âmbito da política de assistência social, desencadeando, como nos lembra Raichelis (2010), ao se referir às redefinições das políticas sociais, novas requisições, demandas e possibilidades ao trabalho do assistente social. Em outros termos, o trabalho do assistente social na operacionalização do Bolsa Família não é alheio à tendência global das políticas sociais. Ao contrário, seu formato focalizado e condicionado representa a expressão máxima da reconfiguração das políticas sociais contemporâneas, imbuídas de argumentos de corte liberal ou neoliberal ${ }^{5}$ e, consequentemente, antagônicas aos argumentos de políticas sociais influenciadas pela lógica da universalidade, como é o caso da política pública de assistência social e dos princípios do Código de Ética profissional.

A execução das atuais políticas por assistentes sociais pelo prisma da ética suscita situações concretas, que envolvem finalidades ético-políticas

4. O PBF no ano de 2014 teve uma cobertura de aproximadamente 14 milhões de famílias, alcançando cerca de 50 milhões de pessoas.

5. Sobre os argumentos de corte liberal ou neoliberal, Sposati (2013, p. 657) pontua que "esses partem da orientação de que é necessário — para favorecer a autoestima, a liberdade, a autonomia do indivíduo superar sua condição improdutiva de beneficiário, introduzindo no modelo de proteção social a disciplina de frequência a treinamentos para que se reduzam situações de dependência que requerem proteção e se ampliem oportunidades de 'exercício de autonomia' isto é, ocupação remunerada de mão de obra, para que o beneficiário se transforme em provedor de sua própria proteção". 
conflitantes, polarizadas entre os valores da lógica focalizada e condicionada do PBF e os princípios do Código de Ética do Serviço Social.

A dimensão ética intrínseca ao modelo condicionado e focalizado do PBF apresenta uma natureza comum aos atuais programas de transferência de renda (PTR) em expansão global; ${ }^{6}$ o beneficiário, sujeito passivo, é transmutado em ativo diante as exigências a serem cumpridas para o recebimento do benefício.

Desse modo, a lógica de ativação do beneficiário rumo à superação individual da sua condição de pobreza prioriza a lógica de autorresponsabilização, o que significa retornar a questão da pobreza para o plano moral, como é o caso das condicionalidades dos PTRs, que responsabilizam o beneficiário pelo acato ou não desses imperativos. Nesse caso, existe uma premissa de que pais pobres são, de alguma forma, culpados se seus filhos não vão à escola ou ao médico.

Entretanto, em consonância com a perspectiva crítica deste artigo, é importante reconhecer que essa premissa de culpabilização é inconsistente com as explicações estruturais da pobreza, tal como aponta Hanlon e Barrientos (apud Ramacciotti, 2014, p. 104): "Existe a possibilidade de que as condicionalidades acabem punindo justamente aqueles que mais precisam de ajuda. As famílias mais vulneráveis são exatamente aquelas as que não conseguem cumprir todas as condicionalidades e perdem seu benefício sendo duplamente penalizadas".

Esse pensamento ressoa a ideologia individualista, na qual cada um é o único culpado por suas derrotas e também o único responsável por suas vitórias, sendo seu efeito nefasto a culpabilização dos beneficiários que não conseguem por si só alcançar o sucesso pessoal.

Para Standing (apud Cobo, 2012), a imposição das condicionalidades pressupõe que uma família pobre deva ser irracional ou incapaz de conhecer seus interesses de longo prazo ou que lhes falta algum tipo de informação vital.

Diante dessa concepção que ressalta o papel de protagonista do beneficiário na superação da sua condição de pobreza, as condicionalidades se enquadram

6. A crise de 2008 deu fôlego novo e legitimidade a um projeto que multiplicou os mecanismos pró-mercado através da disseminação dos programas de garantia de renda mínima focalizados nos mais pobres (Lavinas, 2012). 
na visão paternalista da pobreza, a qual pressupõe, segundo Cobo (2012), que a população pobre não sabe gastar ou agir adequadamente, necessitando que o Estado obrigue-a gastar a renda recebida por meio de benefício de transferência de renda em alimentos - de preferência arroz em vez de iogurtes - ou mandando as crianças para a escola ou cuidando da saúde de todos os familiares. Tais exigências se configuram, para Monnerat (2007), como uma simbologia responsável pela criação de bons pobres e maus pobres, evidenciando a figura de pobre merecedor diante do cidadão de direitos.

Tais programas de transferência de renda focalizados e condicionados carregam consigo a armadilha que os transformam em verdadeiros sistemas executores de critérios e penalidades com códigos de controles, regras e mecanismos que lhe são próprios, cuja tecnicidade garante a "organização da fila" para recebimento de benefícios (Cobo, 2012), além de focalizar e buscar ativar os mais pobres.

Nessa ambiência, as atribuições exigidas ao assistente social se referem à capacidade de treinar o beneficiário para se inserir no mercado, de preferência formal. Segundo Sposati (2013, p. 658; grifos nossos), "esse tipo de atividade deve se submeter a um processo socioeducativo pautado no domínio de procedimentos ocupacionais como cursos de docinhos, salgadinhos, pizza, manicure, depilação, entre outros, pois nesse modo de pensar a proteção advém não de relações e vínculos mas de condições individuais de ativação".

Os valores e as matrizes ideológicas presentes no projeto focalizado e condicionado de PTR são expressos numa relação de pactuação contratual entre o Estado e o cidadão (beneficiário) que, sob os termos da lei, institucionaliza o direito de comando e o dever de obediência (dos beneficiários), sendo o contrato entre o Estado brasileiro e o beneficiário do PBF marcado por relações de controle e penalizações em caso de fraudes. Assim, a gestão das condicionalidades do PBF requer um sistema de controle que, em nome da eficácia,se estrutura de modo a estar munido contra situações fraudulentas.

A preocupação com o controle das fraudes no processo de inclusão e manutenção das famílias beneficiárias no PBF é encontrada na Portaria n. 177, de 16/6/2011, que dispõe sobre os "Procedimentos para a gestão do cadastro único para programas sociais do governo federal”, em que se dedica uma seção 
exclusiva para tratar das medidas de controle e prevenção de fraudes e inconsistências cadastrais:

Seção IV Das Medidas de Controle e Prevenção de Fraudes e Inconsistências Cadastrais. Art. 22. Cabe ao município e ao Distrito Federal responder pela integridade e veracidade dos dados das famílias cadastradas. Art. 23. Havendo evidências de omissão de informações ou de prestação de informações inverídicas pela família, o município e o Distrito Federal adotarão as providências necessárias para apuração dos fatos e averiguação da fidedignidade dos dados cadastrados. $\S 1^{\circ}$ Caso persistam dúvidas acerca da integridade e veracidade dos dados declarados pela família, mesmo após a averiguação por parte do município e do Distrito Federal, deverá ser solicitada ao RF a assinatura de termo especifico, por meio do qual assuma a responsabilidade pela veracidade das informações coletadas, o qual deverá conter, pelo menos, os seguintes itens: I — relação dos componentes da unidade familiar sob sua responsabilidade que não tenham como comprovar a renda declarada; II — ciência de que a omissão da verdade e a prestação de informações inverídicas terão reflexo sobre os beneficios concedidos com base nos dados constantes de seu cadastro; e III - compromisso de atualizar o cadastro de sua família, sempre que houver alguma alteração em sua composição, situação socioeconômica e endereço de residência, informando tais mudanças ao gestor local do CadÚnico e do Programa Bolsa Família (PBF). (Brasil, 2011, p. 7; grifos nossos)

Essa compreensão preocupada com o aspecto punitivo em causa de fraudes no PBF é reforçada no artigo 27 da referida portaria, quando dispõe: "V - adoção de medidas para o controle e a prevenção de fraudes ou inconsistências cadastrais, disponibilizando, ainda, canais para o recebimento de denúncias; VI — adoção de procedimentos que certifiquem a veracidade dos dados; VII - zelo pela guarda e sigilo das informações coletadas e digitadas" (Ibidem, p. 8; grifos nossos).

As dimensões coercitivas e punitivas do PBF ao penalizar famílias por descumprirem condicionalidades acabam por, concomitantemente, contribuir no processo de estigmatização de beneficiários pobres, gerando situações nas quais a vergonha é imposta por fora, sob o status de "descumpridor de condicionalidades". 
A vergonha e o estigma, vinculados à condição de beneficiários de programas sociais, assim como os princípios do workfare, também não são fenômenos recentes, e sua gênese, como já visto, está localizada lá na Lei dos Pobres de 1834, mais especificamente nas workhouses.

Sobre as variáveis do estigma e da vergonha associados à pobreza, o estudo apresentado por Walker (2014, p. 4), em sua obra The shame of poverty [A vergonha da pobreza], alerta sobre o papel do profissional na execução desses programas sociais, ao afirmar que "quando da solicitação de benefícios, funcionários mal preparados agem com base em estereótipos, praticando abusos até que a legitimidade dessas demandas seja comprovada".

A prática de abusos na execução de programas sociais focalizados e condicionados é observada no caso narrado por Torres (2015), quando, relatando ${ }^{7}$ uma experiência de trabalho numa cidade do interior do estado de São Paulo, refere-se a uma escola na qual os professores faziam duas chamadas para controle de frequência dos alunos, uma com a lista dos alunos regulares e outra lista de chamada com os nomes dos alunos beneficiários do PBF. Para a autora, observa-se claramente uma situação em que profissionais, nesse caso da área da educação, violam e fragilizam o campo da convivência enquanto proteção, ao expressarem condições de desigualdades entre os alunos divididos entre beneficiários, por sua vez pobres, e alunos não beneficiários.

Nessa perspectiva reveladora de prática fiscalizadora, coercitiva e estigmatizadora do exercício da vida privada das famílias, as condicionalidades de PTRF são representadas enquanto instâncias disciplinadoras. Segundo Lavergne (2012), com a desculpa de prevenir os riscos sociais, ressuscitamos nos países em desenvolvimento, principalmente na América Latina, as instituições de normalização do século XIX: a escola, a medicina preventiva e as redes de saúde pública e de assistência social.

Outra armadilha no trato com a família beneficiária é a naturalização do seu papel no (des)cumprimento das condicionalidades presentes nos discursos e textos oficiais, e se expressa, segundo Carloto e Mariano (2010), no fato de a

7. Relato registrado no Ciclo de Debates: Trabalho Social com Famílias, promovido pelo Núcleo de Estudos e Pesquisas sobre Políticas e Práticas Sociais com Famílias, do Programa de Mestrado em Políticas Sociais da Universidade Cruzeiro do Sul realizado em 26 de março de 2015. 
família ser encarada como parceira na resolução dos problemas sociais, com a consequente transferência das responsabilidades do Estado para as famílias pobres, legitimando a diminuição do investimento público na área social.

Ainda quando se analisa o eixo condicionado de programas de transferência de renda, outros pesquisadores consideram que as condicionalidades são redundantes, pois remetem a obrigações que os pais já têm, previstas em lei, como enviá-las à escola e vaciná-las, ou exigidas socialmente, como cuidar de sua saúde. Portanto, parecem ser desnecessárias.

Os aspectos negativos das condicionalidades também são aprendidos por pesquisadores pela ótica dos próprios beneficiários. Por exemplo: Alberini (2010), ao entrevistar moradoras da favela São Judas, em Guarulhos (SP), percebe no discurso das beneficiárias que os aspectos negativos do acompanhamento se sobrepõem aos positivos esperados no cuidado à saúde exigido pelo PBF.

Pesquisas revelam que em termos de atendimento à saúde, são muito presentes as reclamações das beneficiárias sobre o atendimento, o agendamento e a dificuldade de acesso aos serviços de saúde. Isto corresponde aos achados de Pinto (2010, p. 96), que afirma que "as condicionalidades de saúde, em relação ao acompanhamento materno-infantil, são muitas vezes encaradas como metas pelos profissionais de saúde e como mera burocracia para os beneficiários".

Em termos específicos da condicionalidade de educação, Carnelossi e Bernardes (2014) revelam que atribuir determinada função à política educacional, mais especificamente à educação básica como instrumento de enfrentamento à pobreza, não apenas simplifica e desqualifica a especificidade pedagógica da educação, como contribui para uma visão reduzida, mascarada e não crítica do problema relativo ao enfrentamento da pobreza no Brasil, revelando uma visão superficial que encobre os conflitos sociais estruturais mais profundos da realidade brasileira. Para as autoras:

Tal consenso aposta na educação, enquanto fórmula messiânica, e está amparada pela crença comum dos brasileiros, marcada pela forte resistência às políticas sociais, universais, incondicionais e redistributivas. No interior desta lógica, a instituição escolar cria oportunidades de mobilidade social por si só, sem envolver a redistribuição de renda e a riqueza socialmente produzida no país. (p. 20) 
Ainda sobre a transferência de renda atrelada à condicionalidade de educação, conclui-se que a educação no trato dos problemas sociais é sempre uma possibilidade, e não uma certeza; não é qualquer escola que faz a diferença no processo de formação cidadã do aluno. Segundo Carnelossi e Bernardes (2014), é nítida que a participação da educação é importante, porém não é suficiente para impactar na realidade brasileira marcada por uma estrutura extremamente desigual, responsável por estatísticas que envergonham a nação quanto ao número inaceitável de brasileiros pobres.

Por ora, a escola é somente uma agência, cujo sentido está fragmentado de seu significado histórico, isso porque compreendemos que a instituição escolar é produto do processo de alienação intrínseca à sociedade capitalista e, no atual estágio de desenvolvimento, entendê-la como mecanismo de transformação não passa de uma suposição idealista e pouco efetiva no enfrentamento à pobreza. A escola e a educação precisam estar inseridas num momento mais amplo de transformação, e é somente desta maneira que as atribuições específicas que são próprias ao conceito de educação e as condições específicas responsáveis pela estrutura desigual da sociedade brasileira serão consideradas. Ao contrário, o que se observa atualmente é a perversidade do papel do Estado, que consiste na não garantia de condições (macro e micro) para a permanência desses jovens na escola. (Carnelossi e Bernardes, 2014, p. 22)

Assim, percebe-se no cotidiano de trabalho vinculado à gestão das condicionalidades de programas de transferências de renda frequentes relatos que expõem diversas frustrações em relação à situação da saúde e da educação nos territórios onde vivem os beneficiários.

Para tanto, importa questionar se esses tipos de PTRs de fato realizam o enfrentamento à exclusão, ou reforçam a vigilância e o controle dos mais pobres (Gough, 2000). Quais são os efeitos na prática das penalidades na realidade cotidiana dos territórios em que vivem os beneficiários? Como o assistente social se posiciona diante as atribuições que lhe são impostas, cuja execução afronta os valores do Código de Ética do Serviço Social e dos princípios da política de assistência social? Como o profissional resiste a essas imposições?

É nesse contexto de políticas sociais permeadas pelos valores do Workfare State que se evidenciam os desafios no trabalho do assistente social na execução 
do PBF e seus rebatimentos valorativos, desafiadores do processo de efetivação do Código de Ética profissional.

\section{Desafios para efetivação do Código de Ética do Serviço Social na execução do PBF}

Os valores norteadores das decisões e atribuições dos assistentes sociais na operacionalização do PBF apontam que as atividades profissionais envolvidas na execução dos procedimentos operacionais, sobretudo aqueles destinados ao registro do descumprimento das condicionalidades, apresentam contornos delimitados por intervenções de natureza burocrática, marcadas meramente por ações de controle e fiscalização.

Nesse contexto, os profissionais do Serviço Social têm suas atribuições assinaladas pelos seguintes imperativos: organizar atividades socioeducativas de ativação, preencher registros, incorporar documentos comprobatórios de ocorrência e sua motivação, avaliar as justificativas apresentadas nos recursos pelos beneficiários, arquivar a documentação que comprova as justificativas alegadas e emitir parecer com a fundamentação da decisão de aplicação ou não das sanções previstas etc.

Esse nível de exigência não é por acaso e reflete os textos e cartilhas oficiais sobre o Paif, disponibilizados pelo Ministério de Desenvolvimento Social (MDS) e direcionados aos técnicos que trabalham no Suas. Ao abordarem o trabalho com as famílias, tais materiais definem como população prioritária do Paif aquelas em "descumprimento de condicionalidades" (Ramacciotti, 2014).

Essa rotina vivenciada pelos profissionais é mediada por sistemas informatizados e expressa, paralela à sua faceta punitiva e estigmatizadora, a gestão tecnocrática desse tipo de PTR.

O contato profissional com o usuário mediado por tecnologia robotizada coloca alguns desafios ao assistente social, visto que sua materialidade restringe a autonomia técnica, além de ferir uma das características principais da profissão, referente à sua natureza relacional. Esse cenário é denominado por Sposati (2011, p. 667) como "robotização do social”, cujas atividades profissionais são 
contaminadas pela percepção que concebe o cidadão enquanto mero fornecedor de dados, sendo a capacidade protetiva traduzida por números e cópias de documentos para a comprovação, por vezes vexatórias e meritocráticas de sua necessidade. Segundo a autora, "a estrita administração de benefícios operados através de sistemas informacionais torna dispensável o relacionamento humano, uma vez que a inflexibilidade ou a homogeneidade de regras de operação, requeridas pelos sistemas informacionais, não permite a incorporação de diferenças ditadas pela particularidade de necessidades".

Frente a tais atividades, o assistente social tem suas ações institucionalmente estabelecidas em ações burocratizadas, tecnicistas e focalizadas, manuseando sistemas informacionais de gestão, que se resume basicamente em gerir transferências de renda via inserção, exclusão, alteração de dados cadastrais e controlar o (des)cumprimento de condicionalidades.

Segundo Iamamoto $(2009$, p. 215), é no convívio e na execução de práticas burocratizadas, tecnicistas e tradicionais ${ }^{8}$ que a profissão redefine sua dimensão técnico-operativa, ilustrando o que denomina por "tecnificação pragmatista" do Serviço Social, caracterizada por "cair-se nas amarras do fetichismo metodológico, cujas intervenções do Serviço Social voltam-se para o aperfeiçoamento do instrumental técnico-operativo, expresso pela sofisticação dos modelos de diagnóstico e planejamento, na busca de uma eficiência que se pretendia asséptica, nos marcos de uma crescente burocratização das atividades".

A natureza burocratizante, tecnicista e controladora da gestão do PBF favorece a presença de posturas profissionais de caráter humilhante, intrusivo e moralizador (Chollet, 2013) na relação com os beneficiários, em especial nos casos de descumprimento das condicionalidades. Assim, "frequentemente se considera o profissional uma espécie de fiscal de rendimentos ou mesmo de examinador de modo de vidas" (Hespanha, 2012, p. 158). Portanto, nessas circunstâncias, as práticas técnico-operativas do Serviço Social se distanciam dos princípios regulados pelo Código de Ética da profissão, pois suas ações favorecem a arbitrariedade dos que decidem sobre o grau de necessidade dos beneficiários.

8. Por Serviço Social tradicional deve-se entender a prática empirista, reiterativa e burocratizada que os agentes realizavam e realizam efetivamente na América Latina (Iamamoto, 2009). 
O aspecto conservador, fiscalizador e coercitivo da prática profissional dos assistentes sociais na relação estabelecida com o usuário/beneficiário é registrado por Medeiros (2008, p. 9), ao relatar a seguinte situação reveladora de casos de controle exercido sobre a vida privada das famílias:

[...] como em uma ocasião, em que foi pedido o desligamento de uma beneficiária, porque a mesma havia, com o recurso recebido, adquirido um celular e que lhe era útil, pois a mesma trabalhava com faxina e necessitava de um telefone para contato, já que o telefone público, existente perto de sua casa, estava constantemente estragado. [...] costuma-se abrir os armários e destampar panelas durante a visita domiciliar semanal, para comprovar o bom uso do dinheiro recebido. Qual a justificativa para tais procedimentos? A resposta dos técnicos era sempre "o Programa exige".

A tensão estabelecida na execução do PBF revela que quando suas demandas são atendidas pelo profissional pautadas restritamente em argumentos legalistas, essas ações acabam por limitar a materialização dos valores comprometidos com uma ética consciente, desde 1986 adotada pela categoria profissional. Nesses casos, conforme revela a pesquisa de Ramacciotti (2014), os profissionais são atropelados por cadernos oficiais ou cursos de capacitação e assimilam as ações propostas de forma automática, reproduzindo posições também automáticas, se assujeitando diante dos textos. A autora citada, em sua dissertação, a partir da perspectiva metodológica empregada na Análise de Discurso Crítica (ADC), conclui que casos assim são reveladores do que se denomina naturalização, ou seja, a aceitação das coisas como elas são, naturalmente fazendo parte do diaadia e, portanto, aceitáveis, não admitindo questionamento ou possibilidade de mudanças (Fairclough, 1995).

Em outras palavras, a execução assujeitada das atuais políticas sociais contemporâneas restringe as condições objetivas de efetivação de condutas profissionais alinhadas com os princípios do Código de Ética profissional, visto que a lógica ideológica implícita nos PTRs operados por assistentes sociais é antagônica aos valores referenciados e conflitante com eles no Código de Ética profissional.

Os valores do Código de Ética vigente do assistente social são comprometidos com a ruptura com o conservadorismo ético-político e com o tradicio- 
nalismo profissional e representam um marco de ruptura com os Códigos de Ética anteriores, que até 1986 eram influenciados por concepções filosóficas pautadas no neotomismo, positivismo e funcionalismo, cujos valores de justiça social eram abstraídos de suas particularidades e determinações históricas, refletindo, por sua vez, em intervenções que visam corrigir condutas morais interpretadas como disfunções e desvios de conduta.

Portanto, observa-se que o profissional que atende as famílias beneficiárias se insere numa situação de conflito entre valores (referenciados no Código de Ética profissional) ou, nos termos de Barroco (2012), desvalores e práticas negativas, cujas posturas profissionais são marcadas por autoritarismo, preconceito, dominação, exploração e discriminação.

Tendo por pressuposto que "nossa prática não pode ser ingenuamente baseada em ideologias, mas crítica e atenta ao mundo" (Ramacciotti, 2014, p. 133), pretendo com este artigo revelar que é no cotidiano do trabalho profissional direcionado as famílias beneficiárias de PTR, apesar da tendência desfavorável à execução de políticas sociais incondicionais e universais, que originam também, com as dificuldades, as potencialidades de efetivação de uma intervenção profissional crítica, capaz de absorver essas orientações oficiais, mas principalmente de transpor condutas e práticas fiscalizatórias, punitivas, moralistas, meritocráticas etc. Para tanto, "é necessário transformar a prática em algo que, em vez de engessar, liberte; que não controle, mas promova cidadania; enfim, algo em que valha a pena trabalhar" (Idem).

Especialmente sobre a prática profissional na gestão das condicionalidades do PBF e em direção a concretude dos valores do Código de Ética é necessário (re)lembrar que o assistente social não pode confundir o seu trabalho com o de polícia, ou aceitar atribuições de segurança e vigilância. Cabe ao profissional recusar tais atribuições e se posicionar de maneira ética no confronto com o conservadorismo institucional (Barroco, 2012). Afinal, segundo o Código de Ética do Serviço Social, é proibido "acatar determinação institucional que fira os princípios e diretrizes deste Código” (CFESS, 1993, p. 22).

Nesse caso, o desafio da profissão, no âmbito da política de assistência social, é resistir ao predomínio da ética da autorresponsabilização, característica desse modelo liberal (re)emergente de política social, e se qualificar em direção ao que Sposati (2013) denomina por "ocupação profissional de resistência 
ético-política". Essa postura valorativa combativa do profissional é amparada no documento oficial do CFESS (2009, p. 16), que trata dos Parâmetros para atuação de assistentes sociais na política de assistência social: "O perfil do(a) assistente social para atuar na política de assistência social deve afastar-se das abordagens tradicionais funcionalistas e pragmáticas, que reforçam as práticas conservadoras que tratam as situações sociais como problemas pessoais que devem ser resolvidos individualmente".

Diante da robotização do social e do controle dos mais pobres, coloca-se o desafio de assegurar no cotidiano do exercício profissional do assistente social ações que se materializem numa direção social em sintonia com os direitos e deveres constantes no Código de Ética profissional, na lei de regulamentação da profissão - Lei n. 8.662/1993 - e com os valores/princípios universais reconhecidos pela política de assistência social.

Em presença do antagonismo de valores entre o PBF, a política de assistência social e o Código de Ética do Serviço Social, é desafiador construir e qualificar estratégias de atuação nas quais prevaleça a autonomia profissional frente às imposições de modelos tecnicistas de execução dessas políticas sociais focalizadas e condicionadas.

É importante registrar que a superação desse desafio está amparada no artigo $3^{\circ}$ do Código de Ética, quando destaca a autonomia profissional capaz de “abster-se, no exercício da profissão, de práticas que caracterizem a censura, o cerceamento da liberdade, o policiamento dos comportamentos, denunciando sua ocorrência aos órgãos competentes" (CFESS, 2009, p. 16; grifos nossos).

Em direção ao enfrentamento desses desafios, é necessário não perder de vista que o Código de Ética não é um documento abstrato. Ao contrário, ele oferece parâmetros para a ação cotidiana do trabalho do assistente social, e sua materialidade se expressa por ser um instrumento de dimensão jurídico-normativa, composto por normas, direitos, deveres e diretrizes concretas que se posicionam em direção a determinado interesse de classe (Barroco, 2012).

Outra estratégia na recusa e posicionamento crítico da categoria profissional diante de condutas que invadem a privacidade e moralizam as atitudes dos beneficiários/usuários se localiza no papel das entidades representativas da categoria profissional (CFESS e Cress) que, segundo Raichelis (2010, p. 754), "ao mesmo tempo se subordinam às normas de enquadramento institucional, 
mas também se organizam e se mobilizam no interior de um coletivo de trabalhadores que repensam a si mesmos e a sua intervenção no campo da ação profissional".

A importância do registro desse posicionamento da categoria profissional também se ressalta, como nos lembra Yazbek (2015), diante do presente cenário de despolitização que torna ainda mais pujante a defesa da resistência e da politização da ação social no nível das práticas cotidianas. Nesse sentido, para a autora, não há espaço para a neutralidade e se destaca a importância de inserção em espaços de lutas coletivas, como fóruns, conselhos e os posicionamentos da categoria profissional, por exemplo através de notas, manifestos etc.

Nesse âmbito, destacam-se os posicionamentos da categoria e das entidades CFESS/Cress contrários à focalização das políticas sociais, como revelam as propostas deliberadas no eixo da seguridade social dos encontros da categoria CFESS/Cress; Carta de Maceió; ${ }^{9}$ CFESS Manifesta - 8 a Conferência Nacional de Assistência Social: Em Defesa do Suas e da Seguridade Social; CFESS Manifesta - Conferência Mundial de Seguridade Social: A Universalização da Seguridade Social Pública é Possível, Necessária e Urgente!

A categoria profissional também se posiciona quanto aos desafios do profissional atuante na política de assistência social a partir do documento anteriormente citado, Parâmetros para atuação de assistentes sociais na política de assistência social, elaborado pelo CFESS, em 2009, e integrante da série Trabalho e Projeto Profissional nas Políticas Sociais.

Especificamente quanto à estrutura condicionada dos PTRs, a categoria profissional tem manifestado sua posição também via deliberações de encontros, tais como a proposta deliberada no $40^{\circ}$ Encontro Nacional CFESS-Cress/2011, no eixo temático da seguridade social, que expressa "desobrigação da contraprestação do usuário no acesso aos serviços e benefícios da assistência social" e as propostas deliberadas no eixo de Comunicação e Seguridade Social do 41 Encontro descentralizado dos Cress da região Sudeste, ocorrido na cidade do Rio de Janeiro, de 3 a 5 de agosto de 2012.

9. Documento público deliberado pelos delegados reunidos no XIX Encontro Nacional CFESS/Cress, na cidade de Macéio (AL), entre os dias 3 e 6 de setembro de 2000, se posicionando na defesa pela luta da seguridade social pública no país. 
Ainda sobre as condicionalidades do PBF, a categoria profissional, através do Núcleo Metropolitano de Assistência Social (Numas) do Cress-SP, se posiciona publicamente em carta pública pelo fim das condicionalidades do PBF (Cress, 2012), que pretende "contribuir com o debate do conjunto CFESS/Cress em direção à construção de um posicionamento da categoria dos (as) assistentes sociais contrários às exigências de condicionalidades presentes nos PTRs e a contraprestação do/a usuária no acesso aos serviços e benefícios da política de assistência social".

Os posicionamentos mencionados da categoria profissional assumidos de maneira coletiva revelam o que Barroco (2012) denomina por "ampliação da consciência ético-política da categoria profissional", processo esse impulsionado após o processo de reconceituação gestado pelo Serviço Social na década de 1960, que permitiu à profissão enfrentar a formação tecnocrática conservadora e construir um projeto ético-político profissional expresso no currículo mínimo de 1982 e nas diretrizes curriculares de 1996 e no Código de Ética de 1986 e 1993, nos quais as políticas sociais e os direitos estão presentes como uma importante mediação para construção de uma nova sociabilidade (CFESS, 2009).

\section{Considerações finais}

A inserção e atribuições exigidas ao assistente social na gestão do PBF não se processam isoladas e desconectadas das transformações conceituais e operacionais das políticas sociais contemporâneas. No entanto, essa "nova" regulação das políticas sociais, delineada por uma lógica focalizada, condicionada e de ativação dos beneficiários, se confronta com os valores e princípios historicamente construídos e representados pelo Código de Ética profissional e pela política de assistência social.

Observa-se um confronto de princípios que coloca de um lado a política de assistência social (influenciada pela lógica do Welfare State) e o Código de Ética do Serviço Social e de outro lado a lógica dos atuais programas de transferência de renda focalizados e condicionados, como é o caso do PBF.

O PBF representa um modelo típico das políticas sociais contemporâneas, e sua operacionalização é reveladora de práticas burocráticas que reforçam a 
vigilância e o controle dos mais pobres. Nesse cenário, as atribuições exigidas ao profissional favorecem a arbitrariedade dos que decidem sobre o grau de necessidade dos beneficiários, restringindo as condições objetivas de efetivação de condutas profissionais alinhadas aos princípios do Código de Ética do Serviço Social.

Tendo por pressuposto que é proibido acatar determinação institucional que fira os princípios e as diretrizes do Código de Ética, o profissional se depara com o desafio de resistir às atribuições que reforçam práticas conservadoras de autorresponsabilização das famílias por sua condição de pobreza.

Daí a conclusão que exalta a importância e a necessidade da análise crítica da realidade social e da apropriação dos princípios e valores do Código de Ética do Serviço Social nas intervenções profissionais com vistas a não sucumbir ao discurso e requisições de instâncias burocráticas típicas das políticas sociais contemporâneas, como é o caso do Programa Bolsa Família.

Recebido em 5/10/2015 - Aprovado em 22/10/2015

\section{Referências bibliográficas}

ALBERINI, M. Nos limites do viver e do sobreviver: o programa Bolsa Família, modos de vida e desenvolvimento social no contexto urbano. Dissertação (Mestrado em Saúde Pública) - Faculdade de Saúde Pública, Universidade de São Paulo, São Paulo, 2010. Disponível em: $<$ http://www.teses.usp.br/teses/disponiveis/6/6136/tde-08112010091817/publico/MarileneAlberini.pdf > . Acesso em: 26 mar. 2013.

BARROCO, Maria Lucia; TERRA, Sylvia Helena. In: CONSELHO FEDERAL DE SERVIÇO SOCIAL (CFESS) (Org.). Código de Ética comentado. São Paulo: Cortez, 2012.

BRASIL. Constituição da República Federativa do Brasil. Brasília, 1990.

. Portaria n.177, de 16 de junho de 2011. Procedimentos para a gestão do Cadastro Único para Programas Sociais do Governo Federal. Diário Oficial [da] República Federativa do Brasil. Poder Executivo, Brasília, 20 jun. 2011. 
CARLOTO, C. M.; MARIANO, S. A. No meio do caminho entre o privado e o público: um debate sobre o papel das mulheres na política de assistência social. Rev. Estud. Fem., Florianópolis, v. 18, n. 2, p. 451-471, 2010. Disponível em: <http://www.scielo. br/pdf/ref/v18n2/09.pdf>. Acesso em: 9 abr. 2013.

CARNELOSSI, Bruna Cristina; BERNARDES, Maria Eliza Mattosinho. A condicionalidade de educação dos programas de transferência de renda: uma análise crítica do programa Bolsa Família. Perspectiva, Florianópolis, v. 32, n. 1, p. 285-313, abr. 2014. Disponível em: <https://periodicos.ufsc.br/index.php/perspectiva/article/view/2175-795X.2014v32n1p285>. Acesso em: 7 set. 2015.

CONSELHO FEDERAL DE SERVIÇO SOCIAL (CFESS). Código de Ética Profissional do Assistente Social. Resolução n. 273, de 13 de março de 1993. Publicada no Diário Oficial da União, Brasília, 30 mar. 1993. Brasília: CFESS, 1997.

. Parâmetros para atuação de assistentes sociais na política de assistência social. Brasília: CFESS, 2009.

CHOLLET, Mona. Uma utopia ao alcance das mãos. Le Monde Diplomatique, São Paulo, ano 6, n. 70, p.19, maio 2013.

COBO, Barbara. Políticas focalizadas de transferência de renda: contextos e desafios. São Paulo: Cortez, 2012.

CONSELHO REGIONAL DE SERVIÇO SOCIAL DE SÃO PAULO (CRESS). $M a-$ nifesto pelo fim das condicionalidades do Programa Bolsa Família. São Paulo: CRESS-SP, 2012.

In: ENCONTRO DESCENTRALIZADO DOS CRESS DA REGIÃO SUDESTE, 41. Relatório Final. Rio de Janeiro: Cress, 2012.

FAIRCLOUGH, N. Critical discourse analysis: the critical study of language. Nova York: Longman, 1995.

GOUGH, I. Do welfare ao workfare: integração social ou trabalho compulsivo? In: SEMINÁRIO EUROPEU: Políticas E Instrumentos De Combate À Pobreza Na União Europeia - A garantia de um rendimento mínimo. Actas..., Almancil/Portugal: União Europeia, 2000.

HESPANHA, Pedro. O (In)sucesso das políticas assistenciais: instituições e agentes. In: GENNARI, Gennari; ALBUQUERQUE, Cristina Albuquerque (Orgs.). Políticas 
públicas e desigualdades sociais: debates e práticas no Brasil e em Portugal. São Paulo: Cultura Académica, 2012. p. 147-161.

IAMAMOTO, Marilda Villela. O Serviço Social na cena contemporânea. In: CFESS/ ABEPSS. Serviço Social: direitos sociais e competências profissionais. Brasília: CFESS/ Abepss, 2009.

JESSOP, Bob. The future of the capitalist State. Cambridge: Polity Press, 2002.

LAVERGNE, R. F. Programa Bolsa Família: uma nova modalidade de biopolítica. Serviço Social \& Sociedade, São Paulo. n. 110, p. 323-344, abr.jun. 2012. Disponível em: <http://www.scielo.br/pdf/sssoc/n110/a06n110.pdf>. Acesso em: 9 abr. 2013.

LAVINAS, Lena. Na contramão dos direitos universais. Politica social e desenvolvimento: o Brasil entre dois projetos, v. 1, 2012. Disponível em: $<$ http://www.politicasocial.net.br/index.php/caderno/caderno-tematico1/137-caderno-1-lena.html>. Acesso em: 10 dez. 2012.

MEDEIROS, M. R. A. Condicionalidades nos programas de transferência de renda: tensão entre direitos e controle dos pobres. 2008. Tese (Doutorado em Serviço Social) - Programa de Pós-Graduação em Serviço Social, Pontifícia Universidade Católica do Rio Grande do Sul, Porto Alegre, 2008.

MONNERAT, G. L. et al. Do direito incondicional à condicionalidade do direito: as contrapartidas do Programa Bolsa Família. Ciência \& Saúde Coletiva, Rio de Janeiro, v. 12, n. 6, p. 1453-1462, 2007.

MOSER, Lilian. A nova geração de políticas sociais no contexto europeu:workfare e medidas de ativação. Katálysis, Florianópolis, v. 14, n. 1, p. 68-77, jan./jun. 2011.

PECK, Jamie. The rise of the Workfare State. Kurswechsel, n. 3, 2003.

PEREIRA, Potyara. A política social entre o direito e o mérito. Welfare State: tendências internacionais, caminhos para o Brasil. Política Social e Desenvolvimento. Campinas, v. 4, p. 19-25, ago. 2014.

PINTO, I. V. Percepções das titulares do Programa Bolsa Família e as repercussões em suas condições de vida: um estudo no Centro de Saúde Escola Germano Sinval Faria, em Manguinhos/RJ, 2009. Dissertação (Mestrado em Ciências na área de Saúde Pública) — Escola Nacional de Saúde Pública Sergio Arouca, Rio de Janeiro, 2010. Disponível em: $<\mathrm{http}: / /$ bvssp.icict.fiocruz.br/pdf/25733_pintoivm.pdf $>$. Acesso em: 31 mar. 2013. 
RAICHELIS, Raquel. Intervenção profissional do assistente social e as condições de trabalho no Suas. Serviço Social \& Sociedade, São Paulo, n. 104, dez. 2010.

RAMACCIOTTI, Nathália Nabor. Percepções das condicionalidades nos programas de transferência de renda: ocaso das beneficiárias do Cras Morro Nova Cintra, Santos, São Paulo. Dissertação (Mestrado em Ensino de Ciências da Saúde) - Universidade Federal de São Paulo, Santos, 2014.

SPOSATI, Aldaíza. Tendências latino-americanas da política social pública no século 21. Katálysis, Florianópolis, v. 14, n. 1, jan./jun. 2011.

. Proteção social e seguridade social no Brasil: pautas para o trabalho do assistente social. Serviço Social \& Sociedade, São Paulo, n. 116, dez. 2013.

TORRES, Abigail. Trabalho social com famílias. Ciclo de Debates: Núcleo de Estudos e Pesquisas sobre políticas e práticas sociais com famílias. Programa de Mestrado em Políticas Sociais. São Paulo: Universidade Cruzeiro do Sul, 2015. [Comunicação oral.]

VANDERBORGHT, Yannick; VAN PARIJS, Philippe. Renda básica de cidadania, argumentos éticos e econômicos. Rio de Janeiro: Record, 2006.

WALKER, R. The shame of poverty. Oxford: Oxford University Press, 2014.

YAZBEK, Carmelita. In: ENCONTRO INTERNACIONAL, 3., ENCONTRO NACIONAL DE POLÍTICA SOCIAL: CAPITALISMO CONTEMPORÂNEO: TENDÊNCIAS E DESAFIOS DA POLÍTICA SOCIAL, 10., Vitória: Ufes, 2015. [Comunicação oral.] 